\title{
Critical appraisal of belatacept for prophylaxis of rejection in kidney transplant patients
}

This article was published in the following Dove Press journal:

Transplant Research and Risk Management

I I April 201 I

Number of times this article has been viewed

\section{Spencer T Martin' \\ Demetra Tsapepas' \\ Steven Gabardi ${ }^{2-5}$ \\ Anil Chandraker ${ }^{2,3}$}

'Department of Pharmacy, New YorkPresbyterian Hospital, New York City, NY, USA; ${ }^{2}$ Harvard Medical School, Boston, MA, USA; ${ }^{3}$ Renal Division, ${ }^{4}$ Department of Pharmacy Services, ${ }^{5}$ Department of Transplant Surgery, Brigham and Women's Hospital,

Boston, MA, USA
Correspondence: Spencer T Martin New York-Presbyterian Hospital/ Columbia Medical Center, $622 \mathrm{~W}$ 168th Street, VC-B, New York City, NY 10032, USA

$\mathrm{Tel}+\mathrm{I} 2123423542$

Fax + I 2123423909

Emailspm9005@nyp.org
Abstract: Belatacept (LEA29Y) is an intravenous biologic for long-term maintenance immunosuppressive therapy in renal transplant recipients. It is currently being reviewed by the United States Food and Drug Administration (FDA) as a prophylactic therapy against acute cellular rejection (ACR) in de novo renal transplant recipients. To provide an in-depth review of the pharmacology, clinical efficacy, safety, and applications of belatacept, a MEDLINE database search was performed for all English-language articles evaluating the pharmacology and efficacy of belatacept, as well as abstracts from recent scientific meetings. Belatacept is a potent inhibitor of $\mathrm{B} 7$ binding to $\mathrm{CD} 28$, a potent T-cell co-stimulatory signal. The B7 ligands are found on the surface of antigen-presenting cells, specifically B7-1 (CD80) and B7-2 (CD86). CD80 and CD86 are essential ligands for CD28, a critical component of costimulation in the three-signal transplant model of T-cell activation. Belatacept has proven noninferiority compared with calcineurin-inhibitor (CNI)-based regimens in the incidence of patient and allograft survival. However, the incidence and severity of ACR has been shown to be increased in patients receiving belatacept therapy. Although rates of ACR are increased in patients receiving belatacept, an overall improvement in allograft function has been described with average improvements in glomerular filtration rates of up to $12-15 \mathrm{~mL} / \mathrm{min}$ higher than CNI-based regimens. The side-effect profile of belatacept has been shown to be similar or improved compared with CNI therapy; however, the risk of malignancy, specifically post-transplant lymphoproliferative disorder is notably higher. Because of the marked increase in the risk of malignancy and ACR, approval of belatacept by the FDA will rely on more robust data from long-term follow-up of currently available data.

Keywords: renal transplantation, immunosuppression

\section{Introduction}

Considerable gains in the field of immunology, specifically the understanding of cellular immunity, have significantly advanced the field of solid organ transplant (SOT). Researchers and clinicians have strived to adequately inhibit the process required for T-cell activation and proliferation without facilitating infectious complications and pharmacologic toxicities. The costimulation pathway is a well known and essential component in T-cell activation; however, current immunosuppressive strategies in SOT do not target it. The B7 family of ligand receptors, B7-1 (CD80) and B7-2 (CD86), found on the surface of antigen-presenting cells (APCs) bind to CD28, a disulfide-linked homodimeric transmembrane protein required for T-cell activation and proliferation. ${ }^{1-3}$ Development of agents that target this essential interaction may result in a more selective process for prophylaxis against allograft rejection while sparing other cellular systems and potential toxicities. 
Abatacept (CTLA4-Ig), an agent approved for use in rheumatoid and polyarticular juvenile idiopathic arthritis, was developed to inhibit the B7 ligands found on APCs. This agent was assessed in animal models of organ transplant. After initial failures, a more potent derivative of abatacept, belatacept (LEA29Y), was developed.

Belatacept represents a paradigm shift in immunosuppressive maintenance therapies for organ transplantation. If approved by the United States Food and Drug Administration (FDA), belatacept would be the first biologic agent marketed for use in long-term maintenance regimen in SOT. To be considered an attractive option for transplant, a biologic agent must overcome several barriers, including possessing the ability to inhibit the immune response in a nondepleting manner without creating excessive immunodeficiency, lacking initial and prolonged immunogenicity and the need for therapeutic drug monitoring (TDM), and offering a reasonable administration route and interval between doses. This manuscript aims to review the pharmacology, efficacy, safety, and clinical application of belatacept in renal transplantation.

We conducted a non-date-restricted MEDLINE search for English-language articles by using the following terms: "belatacept", "LEA29Y”, "CTLA4-Ig”, "renal transplantation", and "organ transplantation". Data were available through to November 2010. Data from abstracts presented at scientific meetings were also included.

\section{Pharmacology and pharmacokinetics}

Belatacept is a derivative of its parent compound, abatacept. ${ }^{4-8}$ Use of abatacept as an immunosuppressive therapy in SOT was originally tested in mice with promising results. ${ }^{9}$ Unfortunately, follow-up in nonhuman primate models of renal transplantation yielded less impressive results. ${ }^{10,11}$ Both compounds have an antagonistic effect on the CD80 and CD86 ligands presented on the surface of APCs. CD80 and CD86 are considered a fundamental component of cellular immunity as the precursors to T-cell activation. ${ }^{1}$ In combination with the activation of the CD3 immunoglobulin on naïve T-cells, binding of CD28 on the surface of a naïve T-cell by CD80/86 results in the production of calcium-calcineurin, Ras-mitogen-activated protein kinase, and nuclear factor- $\kappa \beta .{ }^{12}$ Aside from an increase in cytokine release, this pathway also promotes prolonged cell survival by enhancing the expression of anti-apoptotic molecules, preparation of cellular bioenergenic pathways for improved metabolic demand, and ultimately clonal expansion. ${ }^{13}$ Activation of CD3 via APC major-histocompatability and antigen peptide presentation without costimulation, results in T-cell anergy. This unresponsive state begins a self-destruction cascade resulting in T-cell apoptosis. ${ }^{14,15}$

The development of belatacept for use in SOT was partially based on abatacept's affinity to the CD80/86 receptors. Soluble CTLA-4 was found to have a 2500 -fold higher affinity to CD80 than CD28 and a 500-fold higher affinity to CD86 than CD28. ${ }^{9}$ Although the higher affinity to $\mathrm{CD} 80 / 86$ compared with $\mathrm{CD} 28$ is impressive, with use of CTLA-4Ig, the increase in the compound's affinity to CD80 results in a 100-fold decrease in the overall affinity to CD86, resulting in an incomplete and unequal inhibition of T-cell costimulation. ${ }^{16,17}$ The differences in affinity and abatacept's poor outcomes in animal models of transplant led to the development of a more potent agent with higher selectivity to the CD80/86 ligands on APCs. Belatacept is the result of altering two amino acids in the CD80/86 binding portion of the abatacept compound. This slight change in chemistry resulted in a 4-fold increase in binding affinity to CD86 and a 2-fold increase in binding affinity to CD80 compared with abatacept. Overall, the increase in belatacept's affinity to both CD80/86 results in a 10-fold increase in the ability to inhibit T-cell activation when compared in vitro. ${ }^{9}$ The improvement demonstrated in vitro directly correlated with improved outcomes in the nonhuman primate model for renal transplantation. ${ }^{9}$

Saturation of the CD80/86 ligands by belatacept was determined while patients were enrolled in Phase II and III clinical trials. ${ }^{18}$ Free CD80/86 was determined prior to and after belatacept infusions to determine the degree of saturation. Inhibition of each ligand was found to be concentration dependent. However, saturation at the CD80 site occurred at a belatacept concentration of $0.1 \mu \mathrm{g} / \mathrm{mL}$, and CD86 saturation occurred at a concentration of $1.0 \mu \mathrm{g} / \mathrm{mL}$. It was concluded that appropriate immune suppression would most likely rely on achieving levels of $1.0 \mu \mathrm{g} / \mathrm{mL}$ so that both CD80 and CD86 are adequately inhibited. Incomplete saturation may result in a decreased ability to inhibit costimulation, resulting in T-cell activation and subsequent acute cellular rejection (ACR). The authors concluded that occupancy of CD86 by belatacept may influence the overall level of immunosuppression achieved with belatacept in the clinical setting. ${ }^{18}$ Currently, no clinical trials have adopted this method as a means of assessing or guiding belatacept therapy. 
In regards to maintenance immunosuppression, belatacept's route-of-administration is unique as an intravenous (IV) infusion. The FDA is currently reviewing a less-intensive (LI) dosing regimen for belatacept compared with a more-intensive (MI) dosing schedule. The LI regimen is dosed at $10 \mathrm{mg} / \mathrm{kg}$ on post-operative day (POD) 1 and 5 , then on weeks $2,4,8$, and 12 . Afterward, the dose of belatacept decreases to $5 \mathrm{mg} / \mathrm{kg}$ every 4 weeks for the remainder of the patient's immunosuppressive course. The MI dosing regimen of belatacept is typically dosed $10 \mathrm{mg} / \mathrm{kg}$ on POD 1 and 5 , weeks $2,4,6,8,10,12,16,20$, and 24, and transitioned to $5 \mathrm{mg} / \mathrm{kg}$ every 4 weeks afterward. The IV route requires that patients have access to an infusion-center or home infusion services, or be capable of traveling to their transplant center for the infusion. Although this specific requirement may be a barrier to therapy for some patients, there is a potential benefit in relation to assured adherence to the belatacept portion of therapy. ${ }^{19}$ With appropriate monitoring, a missed infusion of belatacept can immediately result in clinician awareness and appropriate follow-up to ensure administration.

Pharmacokinetic data for belatacept were generated from 984 patients participating in Phase I, II, and III clinical trials. ${ }^{20}$ The half-life of belatacept is about 11 days, allowing for prolonged time intervals between required infusions. Belatacept is defined by a linear two-compartment model with zero-order IV infusion and first-order elimination.
Weight-based dosing for belatacept is supported by increased clearance and volume of central compartment with increasing baseline bodyweight when dosed between 5 and $10 \mathrm{mg} / \mathrm{kg}$. Demographic parameters, including gender, race, age, renal and hepatic function, and diabetes, were not found to impact belatacept pharmacokinetics. ${ }^{20}$

\section{Clinical efficacy}

In a Phase II trial, Vincenti et al demonstrated noninferiority of belatacept to cyclosporin for preventing clinically suspected biopsy-proven acute rejection (BPAR) in adult renal transplant recipients (RTRs) at 6 months (Table 1). ${ }^{19}$ The study was an open-label, partially blinded, randomized, parallel-group, multicenter trial conducted between March 2001 and December 2003. A total of 218 non-HLA identical adult patients receiving a living or deceased donor renal transplant were included in the study. Higher-risk patients (prior renal transplant, historical peak panel-reactive antibody [PRA] $>20 \%$ ) who were considered at increased risk for ACR could make up no more than $10 \%$ of the study population. Patients were excluded from participation if the etiology of their end stage renal disease was from a disease that could recur in the allograft, had active infection with hepatitis B, hepatitis C, or HIV (human immunodeficiency virus), a history or evidence of malignancy, positive T-cell complement-dependent cytotoxicity crossmatch,

Table I Summary of Belatacept Phase II and III clinical trials

\begin{tabular}{|c|c|c|c|c|c|c|c|c|}
\hline Author & Year & Follow-Up & Intervention & ACR n (\%) & $\begin{array}{l}\text { Patient Survival } \\
\text { n (\%) }\end{array}$ & $\begin{array}{l}\text { Graft Survival } \\
\text { n (\%) }\end{array}$ & $\begin{array}{l}\text { Malignancy } \\
\text { n (\%) }\end{array}$ & $\begin{array}{l}\text { PTLD n } \\
\text { (\%) }\end{array}$ \\
\hline \multirow[t]{3}{*}{ Vincenti ${ }^{19}$} & 2005 & 12 months & MI Belatacept $(n=74)$ & $5(7)$ & $73(99)$ & $71(96)$ & $4(5)^{a}$ & $3(4)^{a}$ \\
\hline & & & LI Belatacept $(n=7 I)$ & $4(6)$ & $71(100)$ & $70(99)$ & $0(0)$ & $0(0)$ \\
\hline & & & Ciclosporin $(n=73)$ & $6(8)$ & $69(93)$ & 71 (97) & $2(3)$ & $0(0)$ \\
\hline \multirow{3}{*}{$\begin{array}{l}\text { BENEFIT; } \\
\text { Vincenti }^{22}\end{array}$} & 2010 & 12 months & MI Belatacept $(n=219)$ & $49(22)$ & $213(97)$ & $215(98)$ & $7(4)^{b}$ & $3(I)^{b}$ \\
\hline & & & LI Belatacept $(n=226)$ & $39(17)$ & $222(98)$ & $221(95)$ & $4(2)$ & $2(1)$ \\
\hline & & & Ciclosporin $(n=22 I)$ & $16(7)$ & $214(97)$ & $213(96)$ & $I(I)$ & $I(1)$ \\
\hline \multirow{3}{*}{$\begin{array}{l}\text { BENEFIT-EXT; } \\
\text { Durrbach }^{24}\end{array}$} & 2010 & 12 months & MI Belatacept $(\mathrm{n}=184)$ & $33(18)$ & $176(96)$ & $167(91)$ & $5(3)^{c}$ & $2(I)^{c}$ \\
\hline & & & LI Belatacept $(n=175)$ & $31(18)$ & $|7|(98)$ & $159(9 \mid)$ & $5(3)^{c}$ & $3(2)^{c}$ \\
\hline & & & Ciclosporin $(n=184)$ & $26(14)$ & $176(96)$ & $164(89)$ & $6(3)$ & $0(0)$ \\
\hline \multirow[t]{3}{*}{ Ferguson ${ }^{25}$} & 2011 & 12 months & $\begin{array}{l}\text { Belatacept }+ \text { Mycophenolate } \\
\text { Mofetil }(n=33)\end{array}$ & $4(12)$ & $32(97)$ & 31 (94) & $0(0)$ & $0(0)$ \\
\hline & & & Belatacept + Sirolimus $(n=26)$ & I (4) & $26(100)$ & $24(92)$ & I (4) & $0(0)$ \\
\hline & & & $\begin{array}{l}\text { Tacrolimus + Mycophenolate } \\
\text { Mofetil }(\mathrm{n}=30)\end{array}$ & I (3) & $30(100)$ & $30(100)$ & I (3) & $0(0)$ \\
\hline
\end{tabular}

Notes: ${ }^{\mathrm{T}}$ Two additional patients developed PTLD 2 and 13 months after the trial end-date, ${ }^{\mathrm{b}}$ Two additional patients developed PTLD after the trial end-date at 12 months, 'One additional patient developed PTLD after the trial end-date at 12 months.

Abbreviations: ACR, acute cellular rejection; LI, less intensive belatacept regimen; MI, more intensive belatacept regimen; PTLD, post-transplant lymphoproliferative disorder. 
history of drug or alcohol abuse and psychotic illness, donors $>60$ years of age or donation after cardiac death (DCD), or a cold ischemia time $>36$ hours. All patients received basiliximab induction, $20 \mathrm{mg}$ IV on POD 0 and 4, and maintenance therapy with $2 \mathrm{~g} /$ day mycophenolate mofetil, a corticosteroid taper (500 mg on POD 0 decreased to no less than $5 \mathrm{mg}$ per day by month 4$)$, and study drug. Patients were randomized to an $\mathrm{MI}$ belatacept regimen (0-6 months: $10 \mathrm{mg} / \mathrm{kg}$ on days $1,5,15,29,43,57,71,85,113,141$, and 169 , followed by $7-12$ months: $5 \mathrm{mg} / \mathrm{kg}$ every 4 or 8 weeks), an LI belatacept regimen (0-3 months: $10 \mathrm{mg} / \mathrm{kg}$ on days $1,15,29,57$, and 85 , followed by 3-12 months: $5 \mathrm{mg} / \mathrm{kg}$ every 4 or 8 weeks), or cyclosporin (target trough level: $0-1$ months: $150-400 \mathrm{ng} / \mathrm{mL}$ and $2-12$ months: 150-300 ng/mL). All patients underwent protocol biopsies at baseline and month 12 and plasma clearance of iohexol was utilized to assess glomerular filtration rates (GFR) at months 1,6 , and $12 .{ }^{19}$

The primary endpoint of noninferiority in the prevention of ACR at 6 months was defined clinicopathologically as an increase in serum creatinine of $0.5 \mathrm{mg} / \mathrm{dL}$ along with findings on renal biopsy consistent with rejection. ${ }^{19}$ Incidence of ACR in each study group was similar and the inferiority margin of $20 \%$ was met within all three groups. ACR occurred in $7 \%, 6 \%$, and $8 \%$ of patients in the MI belatacept group $(n=74)$, LI belatacept group $(n=71)$, and cyclosporin group $(n=73)$, respectively. Severe rejection episodes (Banff IIB) which required antithymocyte therapy occurred in $4 \%, 7 \%$, and $3 \%$ of the MI, LI, and cyclosporin groups, respectively. Subclinical rejection at month 6 was more common in the LI belatacept group (20\%) compared with the MI belatacept (9\%) and cyclosporin groups (11\%). No patients experienced ACR after the 6-month study period. Chronic allograft nephropathy was more prevalent in the cyclosporin group (44\%) as compared with both the MI (29\%) and LI (20\%) belatacept groups. Measured GFR at 12 months was significantly higher in both belatacept groups; $\mathrm{MI}(66.3 \mathrm{~mL} / \mathrm{min})$ to cyclosporin $(53.5 \mathrm{~mL} / \mathrm{min})(P=0.01)$ and $\mathrm{LI}(62.1 \mathrm{~mL} /$ $\min )$ to cyclosporin $(P=0.04)$. Patient and graft survival were similar in all treatment groups at the end of the study. ${ }^{19}$

Long-term data on belatacept were evaluated in an open-label extension of this trial. ${ }^{21}$ Approximately $60 \%$ of patients enrolled in the original trial $(\mathrm{MI}=56$; $\mathrm{LI}=46$; cyclosporin $=26$ ) remained in the extension analysis. Median follow-up during this period was 5 years (range: 1-7 years). Safety and efficacy outcomes were analyzed using combined MI and LI belatacept-treated patients because this study was not powered to detect a difference in outcomes between the two treatment arms. The average calculated GFR remained stable for belatacept-treated patients from month 12 to 60 , $75.8 \pm 20.1 \mathrm{~mL} / \mathrm{min}$ and $77.2 \pm 22.7 \mathrm{~mL} / \mathrm{min}$ respectively but decreased in patients maintained on cyclosporin therapy from $74.4 \pm 23.7 \mathrm{~mL} / \mathrm{min}$ to $59.3 \pm 15.3 \mathrm{~mL} / \mathrm{min}$. Patient and graft survival were $97 \%$ and $99 \%$ for belatacept-treated patients and $92 \%$ and $100 \%$ for cyclosporin treated patients. Late BPAR only occurred in the belatacept-treated patients $(6 \%)$; two episodes in the MI group and four episodes in the LI group. ${ }^{21}$

A Phase III study of belatacept-based immunosuppression regimens versus cyclosporin in renal transplant recipients (BENEFIT) was a 3-year, randomized, active-controlled, partially blinded, parallel group, multicenter study conducted in 100 centers worldwide (Table 1). ${ }^{22}$ Treatment with two belatacept-based regimens were compared with a cyclosporin-based regimen evaluating three co-primary outcomes, a composite patient and graft survival, composite renal impairment endpoint and the incidence of ACR at 12 months. All adult RTRs receiving grafts from living or deceased donors with a cold ischemia time less than 24 hours were eligible for participation. Exclusion criteria included receiving a DCD or extended criteria donor (ECD), prior or concurrent nonrenal transplant, or having a PRA of $>50 \%$ or $>30 \%$ in patients being re-transplanted. Of the 666 patients transplanted, 526 completed the 12-month treatment phase. ${ }^{22}$

All patients received basiliximab induction, $20 \mathrm{mg}$ IV on POD 0 and 4, and maintenance therapy with mycophenolate mofetil (2 g/day), and corticosteroids (500 mg on POD 0 and no less than $2.5 \mathrm{mg}$ /day by POD 15) in addition to study drug. ${ }^{22}$ Patients were randomized in a 1:1:1 fashion to an MI belatacept regimen $(10 \mathrm{mg} / \mathrm{kg}$ on days 1 and 5 and weeks 2 , $4,6,8,10,12,16,20$, and 24 , then $5 \mathrm{mg} / \mathrm{kg}$ every 4 weeks), an LI belatacept regimen $(10 \mathrm{mg} / \mathrm{kg}$ on days 1 and 5 , and weeks $2,4,8$, and 12 , then $5 \mathrm{mg} / \mathrm{kg}$ every 4 weeks), or cyclosporin (target trough level: 0-1 months: $150-300 \mathrm{ng} / \mathrm{mL}$ and 2-12 months: $100-250 \mathrm{ng} / \mathrm{mL}){ }^{22}$

Both belatacept regimens met the noninferiority margin of $10 \%$ as well as a more rigorous threshold of $5 \%$ for the coprimary endpoint of patient and graft survival compared with the cyclosporin group. ${ }^{22}$ Evaluation of the coprimary composite renal impairment endpoint demonstrated that renal function was superior in patients who were randomized to belatacept versus cyclosporin. The incidence of ACR at 12 months was $22 \%$ in the MI group, $17 \%$ in the LI group, and $7 \%$ in the cyclosporin group. The LI group was deemed noninferior for preventing ACR compared with 
the cyclosporin by satisfying a $20 \%$ margin for comparison; however, the MI group exceeded the inferiority margin and was therefore statistically inferior to the cyclosporin group - more patients receiving belatacept MI experienced Banff grade IIB rejection episodes. The mean measured GFR was $13-15 \mathrm{~mL} / \mathrm{min}$ higher in the belatacept group despite a higher incidence of BPAR. All patients underwent a protocol biopsy at week 52; however, the study advocated that investigators perform biopsies if there were reasons for clinical suspicion of rejection: unexplained rise in serum creatinine $\geq 25 \%$ from baseline, unexplained decrease in urine output, fever and graft tenderness, or serum creatinine that remained elevated for 14 days posttransplant. ${ }^{22}$

\section{Extended criteria donors}

The decline in availability of organs for transplantation has led to increased utilization of ECD to increase the donor pool. Accepting an ECD organ decreases transplant list waiting time and decreases a patient's risk of cardiovascular complications that are associated with end-stage renal disease. However, ECD RTRs typically experience higher rates of delayed graft function (DGF), increased incidence of ACR, and generally experience decreased allograft survival time. ${ }^{23}$

A Phase III trial (BENEFIT-EXT) was developed to evaluate whether belatacept would provide similar patient and graft survival as well as superior renal function when used as first-line immunosuppression versus cyclosporin specifically in patients receiving ECD organs (Table 1) ${ }^{24}$ Adult patients who received a renal allograft from an ECD donor, defined as greater than or equal to 60 years of age; or 50 years of age or older with at least two risk factors including cerebral vascular accident, hypertension, or a serum creatinine of greater than $1.5 \mathrm{mg} / \mathrm{dL}$; or an anticipated cold ischemia time of 24 hours or greater; or DCD. Patients were randomized to one of three groups: MI belatacept regimen $(10 \mathrm{mg} / \mathrm{kg}$ on days 1 and 5 , and weeks 2, 4, 6, 8, 10, 12, 16, 20, and 24 , then $5 \mathrm{mg} / \mathrm{kg}$ every 4 weeks); an LI belatacept regimen $(10 \mathrm{mg} / \mathrm{kg}$ on days 1 and 5 , and weeks $2,4,8$, and 12, then $5 \mathrm{mg} / \mathrm{kg}$ every 4 weeks); or cyclosporin (0-1 months trough levels: $150-300 \mathrm{ng} / \mathrm{mL}$ then $2-12$ months trough levels: $100-250 \mathrm{ng} / \mathrm{mL}$ ) in a 1:1:1 fashion. All patients received basiliximab induction at the time of transplant (20 mg IV on POD 1 and 5) as well as mycophenolate mofetil (2 g/day in divided doses) and corticosteroids (500 $\mathrm{mg}$ on POD 0 tapered over 15 days to at least $2.5 \mathrm{mg}$ /day) for maintenance immunosuppression in addition to the treatment arm to which they were randomized. Patients in the cyclosporin treatment group were allowed T-cell-depleting agents if DGF occurred. Mild rejection episodes were treated with corticosteroid pulses, and T-cell depleting agents were permitted as treatment for severe or resistant rejection. ${ }^{24}$

A total of 543 of the 578 patients randomized in this study were transplanted $(\mathrm{MI}=184 ; \mathrm{LI}=175$; cyclosporin $=184) .{ }^{24}$ Demographic parameters, as well as the percentage of patients with DGF, were similar between the three treatment groups. Both belatacept groups were found to be noninferior to cyclosporin for the composite primary end-point of patient and graft survival, the pre-specified noninferiority margin was $10 \%$. Graft loss caused by ACR, thrombosis, or technical causes was similar between all groups. The co-primary composite end-point of renal impairment (GFR $<60 \mathrm{~mL} / \mathrm{min}$ at 12 months or a decrease of $\geq 10 \mathrm{~mL} / \mathrm{min}$ from postoperative months 3-12) was significantly improved in the MI belatacept-treatment group versus cyclosporin $(P=0.0083)$. Although improvement in renal function for the LI belatacept-group did not reach statistical significance, GFR in this group was $6-8 \mathrm{~mL} / \mathrm{min}$ higher than the cyclosporin group. GFR improvement was noted despite the fact that patients in all treatment groups experienced DGF. ${ }^{24}$

Biopsy-proven chronic allograft nephropathy (45\%-52\% of patients) and severe chronic allograft nephropathy (4\%-7\% of patients) at 12 months was similar between all treatment groups. ${ }^{24}$ The $20 \%$ noninferiority margin for incidence of ACR in this study was achieved by both MI and LI belatacept groups. Of note, nearly all rejection episodes occurred within the first 6 months post-transplant, but more Banff IIB rejection episodes developed in the belatacept groups $(\mathrm{MI}=9 \% ; \mathrm{LI}=5 \%)$ when compared with cyclosporin $(3 \%)$, and more patients in the MI belatacept group had more than one episode of rejection $(n=5)$ versus LI belatacept $(n=1)$ and cyclosporin group $(n=2){ }^{24}$

\section{Steroid and calcineurin inhibitor avoidance}

A 1-year, randomized, open-label, Phase II, multicenter trial was conducted to evaluate the efficacy and safety of tacrolimus-based immunosuppression versus two belatacept-based regimens where steroid and calcineurin inhibitor avoidance was attempted (Table 1). ${ }^{25}$ A total of 89 Epstein-Barr virus (EBV) seropositive adults receiving a primary living donor or standard criteria deceased donor kidney transplant were randomized in a 1:1:1 fashion to one of three treatment arms: 1) belatacept and mycophenolate mofetil $1000 \mathrm{mg}$ twice daily ( $\mathrm{B}+\mathrm{MMF} ; \mathrm{n}=33)$; 2) belatacept and sirolimus $(\mathrm{B}+\mathrm{SRL} ; \mathrm{n}=26)$; or 3$)$ tacrolimus plus mycophenolate 
mofetil (TAC+MMF; $n=30$ ). Sirolimus goal trough levels in the B+SRL group were $7-12 \mathrm{ng} / \mathrm{mL}$ for the first 6 months post-transplant and $5-10 \mathrm{ng} / \mathrm{mL}$ for the remainder of the study. Patients receiving tacrolimus in the B+TAC group had goal troughs of $8-12 \mathrm{ng} / \mathrm{mL}$ for the first month posttransplant and 5-10 ng/mL for the remainder of the study. All patients received rabbit-antithymocyte globulin induction (6 mg/kg maximum) and withdrawal of corticosteroids by POD 4. Intravenous methylprednisolone was administered at doses of 500, 250, 125, and $60 \mathrm{mg}$ on POD 1, 2, 3, and 4 , respectively. Belatacept maintenance dosing was similar to previously described MI regimens: $10 \mathrm{mg} / \mathrm{kg}$ on POD 1 and 5 , then once every 2 weeks through month 3 , every 4 weeks through month 6 , and $5 \mathrm{mg} / \mathrm{kg}$ every 4 weeks thereafter. $^{25}$

The primary endpoint was incidence of ACR at 6 months, which occurred at a rate of $12 \%, 4 \%$, and $3 \%$ in the $\mathrm{B}+\mathrm{MMF}, \mathrm{B}+\mathrm{SRL}$, and TAC+MMF groups, respectively. ${ }^{25}$ Most rejection episodes occurred within the first 3 months posttransplant; however, one episode in the B+MMF group occurred after month 6 . The composite end-point of patient and graft survival was similar between treatment groups, 91\%, $92 \%$, and $100 \%$ in the B+MMF, B+SRL, and TAC+MMF groups, respectively. One patient in the $\mathrm{B}+\mathrm{MMF}$ group died during the study period. Both the $\mathrm{B}+\mathrm{MMF}$ and $\mathrm{B}+\mathrm{SRL}$ group had two patients who experienced graft loss. The mean calculated GFR for each group was $63.6 \pm 27.3 \mathrm{~mL} / \mathrm{min}$, $61.8 \pm 30.7 \mathrm{~mL} / \mathrm{min}$ and $54.0 \pm 15.0 \mathrm{~mL} / \mathrm{min}$ for the $\mathrm{B}+\mathrm{MMF}$, $\mathrm{B}+\mathrm{SRL}$, and TAC+MMF groups, respectively. CNI and steroid avoidance was successful in $73 \%$ of the B+MMF and $77 \%$ of the B+SRL treated patients, and steroid avoidance alone was achieved in $93 \%$ of TAC+MMF treated patients. ${ }^{25}$

\section{Converting from a calcineurin inhibitor-based regimen to belatacept}

Several studies have demonstrated that belatacept is as efficacious as CNIs in preventing acute rejection and is associated with improved outcomes in GFR for RTR. Substitution of belatacept for a CNI may have the ability to spare renal transplant patients from the nephrotoxic and cardiovascular side effects of CNIs. Results from a Phase II study to evaluate conversion from a CNI-based regimen to belatacept have been reported in abstract form. ${ }^{26}$ This randomized, open-label study included 171 RTRs, 6-36 months post-transplant, who were receiving CNI-based immunosuppression and had stable renal function $\left(M D R D\right.$ GFR $\geq 35 \mathrm{~mL} / \mathrm{min} / 1.73 \mathrm{~m}^{2}$ and $\leq 75 \mathrm{~mL} / \mathrm{min} / 1.73 \mathrm{~m}^{2}$ ). Patients were randomized into one of two treatment groups: conversion to belatacept $5 \mathrm{mg} / \mathrm{kg}$ every 4 weeks with CNI discontinuation $(n=83)$; or continued CNI therapy $(n=88)$. All patients remained on other maintenance immunosuppressive agents they were taking; mycophenolate, sirolimus, azathioprine, and corticosteroids. ${ }^{26}$

At month 12, the primary outcome of mean change in MDRD GFR from baseline increased by $7.0 \mathrm{~mL} / \mathrm{min} \pm 11.99$ in the belatacept group and by $2.1 \mathrm{~mL} / \mathrm{min} \pm 10.34$ in the CNI group. ${ }^{26}$ Six patients $(7 \%)$ who underwent belatacept conversion experienced an ACR episode within the first 6 months compared with none in the CNI group. Patient and graft survival was $100 \%$ and $99 \%$ in the belatacept and CNI groups, respectively. ${ }^{26}$

\section{Adverse effects Malignancy}

The largest belatacept trial to date, the Phase III BENEFIT trial, found that the incidence of malignancy in belatacept was dramatically higher than that of cyclosporin. ${ }^{22}$ Of the 445 patients receiving belatacept, 11 developed malignancy $(2.5 \%)$ compared with only one patient of the 221 patients receiving cyclosporin $(0.5 \%)$. Perhaps more importantly, 5 of the 11 patients in the belatacept who developed malignancy in the belatacept arms were diagnosed with post-transplant lymphoproliferative disorder (PTLD), two of which involved the central nervous system (CNS). Of the 359 patients enrolled in the two belatacept groups in the BENEFIT-EXT Phase III trial, eight $(2.2 \%)$ developed malignancy. ${ }^{24}$ In comparison, six patients $(3.3 \%)$ in the cyclosporin group developed cancer. However, five of the eight patients in the belatacept group were diagnosed with PTLD, four of which involved the CNS. The Phase II trial published by Vincenti and his colleague reported two (1.4\%) cases of malignancy, one of which was diagnosed as PTLD, in the belatacept arm compared with two (2.7\%) malignancies in the cyclosporin arm. ${ }^{19}$ Additionally, two more cases of PTLD were diagnosed in the MI dosing group 2 and 13 months after the trial had closed and the patients had been switched to conventional immunosuppressive regimens.

Of the three major trials described above, a total of 13 patients in the belatacept groups have been diagnosed with PTLD (1.4\%) compared with only one cyclosporin patient $(0.2 \%){ }^{19,22,24}$ Of the 13 cases of PTLD identified, six developed PTLD of the CNS. This is a concerning diagnosis, considering that only three case series have documented a total of 45 patients with PTLD involving the CNS in SOT. ${ }^{27-29}$ 
The majority of patients who developed PTLD had known risk factors for PTLD, including EBV seronegative recipients pre-transplant, receiving lymphocyte-cell-depleting agents, and having a primary EBV infection. A recent Phase II analysis that excluded transplant recipients who were EBV seronegative pre-transplant has yet to report any cases of PTLD. ${ }^{25}$ The absence of PTLD in this analysis may be evidence enough to avoid use of belatacept in those recipients who are EBV seronegative pre-transplant.

\section{Infectious complications}

Incidence of CMV infection was found to be similar when comparing the MI, LI, and cyclosporin groups regardless of analysis. CMV was diagnosed in a total of 96 belatacept patients $(10.1 \%)$ compared with $56(11.7 \%)$ cyclosporin patients in the three pivotal belatacept trials. ${ }^{19,22,24}$ Urinary tract infections (UTI), ranging from minor to severe, were the most common infectious complication noted, occurring in $263(29.1 \%)$ of the 949 belatacept patients with available data. ${ }^{19,22,24}$ Each analysis determined that the incidence of UTI was similar in the belatacept groups when compared with the cyclosporin arms.

The Phase III trials reported on similar infectious outcomes. Both the BENEFIT and BENEFIT-EXT trials determined that there were no differences in the incidence of fungal infections, BK virus, pneumonia, upper respiratory infection, and infectious gastroenteritis when comparing the MI and LI belatacept arms with cyclosporin. ${ }^{22,24}$ However, the BENEFIT-EXT trial did report a single case of pneumocystis jirovecii pneumonia in both the LI and MI belatacept arms. ${ }^{24}$ Also, a single case of progressive multifocal leukoencephalopathy (PML) was also reported in a patient who was enrolled in the MI group after completion of the 12 month analysis. ${ }^{24}$

\section{Cardiovascular and metabolic}

An anticipated benefit of belatacept compared with a CNI based regimen, aside from improvements in GFR over time, is the avoidance of adverse metabolic outcomes. The BENEFIT trial demonstrated a decrease in triglyceride levels from baseline for both the MI $(-17.0 \pm 7.0 \mathrm{mg} /$ $\mathrm{dL} ; P=0.0165)$ and LI $(-21.2 \pm 6.9 \mathrm{mg} / \mathrm{dL} ; P=0.0047)$ belatacept groups compared with an increase in the cyclosporin group $(6.6 \pm 6.9 \mathrm{mg} / \mathrm{dL}) .{ }^{22}$ Triglycerides were also found to decrease in the MI $(-1.0 \pm 9.5 \mathrm{mg} /$ $\mathrm{dL} ; P=0.0106)$ and LI $(-18.2 \pm 9.2 \mathrm{mg} / \mathrm{dL} ; P=0.0001)$ belatacept groups compared with a cyclosporin increase in the BENEFIT-EXT trial. ${ }^{24}$
An increase in non-HDL cholesterol from baseline was seen in all three groups in the BENEFIT trial; however, they were less severe in the MI $(8.1 \pm 2.8 \mathrm{mg} / \mathrm{dL} ; P=0.0115)$ and LI $(8.0 \pm 2.8 \mathrm{mg} / \mathrm{dL} ; P=0.0104)$ belatacept groups compared with cyclosporin $(18.3 \pm 2.8 \mathrm{mg} / \mathrm{dL}) .{ }^{22}$ The BENEFIT-EXT trial also found that non-HDL cholesterol in the cyclosporin arm $(29.3 \pm 3.8 \mathrm{mg} / \mathrm{dL} ; P=0.0016)$ had increased significantly from baseline when compared with the MI $(12.6 \pm 3.6 \mathrm{mg} / \mathrm{dL} ; P=0.0016)$ and LI $(11.2 \pm 3.6 \mathrm{mg} / \mathrm{dL}$; $P=0.0006)$ belatacept patients. ${ }^{24}$

Mean systolic blood pressure was significantly reduced in both the MI $(133 \pm 16.2 \mathrm{mmHg} ; P=0.001)$ and LI (131 $\pm 16.5 \mathrm{mmHg} ; P \leq 0.0001)$ regimens compared with cyclosporin $(139 \pm 20.1 \mathrm{mmHg})$ in the BENEFIT trial. ${ }^{22}$ Diastolic blood pressure also improved in the MI $(79 \pm 11.6 \mathrm{mmHg} ; P=0.0273)$ and LI $(79 \pm 10.9 \mathrm{mmHg}$; $P=0.005)$ belatacept groups compared to cyclosporin $(82 \pm 11.2 \mathrm{mmHg})$. Finally, incidence of new onset diabetes after transplant (NODAT) occurred in 28 (3.5\%) of the 804 belatacept patients included in both the BENEFIT and BENEFIT-EXT trials compared with 27 (6.7\%) of the 405 cyclosporin patients included. ${ }^{22,24}$

\section{Infusion related reactions}

Acute infusion-related adverse events, defined as a reaction within the first hour of infusion, occurred in 24 (2.5\%) of the 949 belatacept patients studied. ${ }^{19,22,24}$ One patient experienced a prolonged hypotensive episode that was considered severe enough to discontinue belatacept therapy. The remaining 23 episodes of infusion-related reactions were all considered mild to moderate in nature and did not require the cessation of belatacept therapy. ${ }^{19,22,24}$

\section{Discussion}

Belatacept is a novel immunosuppressive agent that offers a potential new option for prophylaxis of ACR in RTR. The mechanism of action is unique compared with currently available immunosuppressives in that costimulation required for T-cell activation is inhibited. If approved, belatacept would be the first biologic compound developed for the purpose of maintenance immunosuppression in SOT.

The increased rates and severity of ACR demonstrated in the belatacept groups requires careful consideration. It is well documented that early onset ACR in the months immediately following renal transplantation is one of the most substantial predictors for poor long-term allograft 
function and survival. ${ }^{30-33}$ However, more recently published data suggest that despite a decrease in overall ACR rates and severity, trends in long-term graft function remain unchanged. ${ }^{34}$ This phenomena might be explained by the acute and chronic nephrotoxic effects that are associated with current immunosuppressive regimens. ${ }^{35}$ The $13-15 \mathrm{~mL} /$ min improvement in GFR seen with belatacept patients compared with cyclosporin could potentially correlate with improved long-term outcomes despite the increased incidence of ACR. ${ }^{22}$ However, long-term results of allograft function and survival from the belatacept Phase III trials previously described are required before any conclusions on long-term outcomes can be established.

Malignancy not withstanding, the safety profile of belatacept appears to be relatively benign. Significant improvements in metabolic and cardiovascular risk factors compared with Cyclosporin make belatacept an attractive option, especially in an end-stage renal disease population with an increased risk of death due to cardiovascular complications. ${ }^{36,37}$ Avoidance of infectious complications, including bacterial, $\mathrm{CMV}$, BK virus, and fungal infections has not favored any one agent.

The increased incidence of malignancy documented with belatacept use is of critical concern. More specifically, the 13 cases of PTLD among 949 patients receiving belatacept compared with only one case in 478 cyclosporin-treated patients demands notice. An even more troubling trend is that 6 of the 13 PTLD cases had CNS. An explanation for this association remains elusive. However, avoidance of known risk factors has demonstrated a significant reduction in the incidence of PTLD. A small analysis excluding RTR who were EBV naïve at time of transplant $(n=59)$ has not resulted in any documented cases of PTLD. ${ }^{25}$ Interestingly, all of the patients received T-cell-depleting induction therapy which is a known risk factor for development of PTLD. ${ }^{38-40}$ At this time, belatacept use may be warranted in those patients who are EBV naïve and may benefit from belatacept as a rescue therapy with appropriate monitoring and prophylaxis for PTLD. Increased rates of ACR, seen with belatacept, are typically associated with a decreased incidence of malignancy in solid organ transplantation. Belatacept seems to defy this reasoning by causing an increased incidence in both ACR and malignancy when compared with cyclosporin. Unfortunately, a cause for this atypical relationship has not been determined but requires attention when administering belatacept.
The incidence of PTLD is being reviewed by the FDA during the approval process. In March 2010, the FDA's Cardiovascular and Renal Drugs Advisory Committee voted to recommend the approval of belatacept, but it also recommended that belatacept be approved with a risk evaluation and mitigation strategy (REMS) program due to the risk of PTLD and infectious complications. ${ }^{41}$ The recommended belatacept REMS program would aim to manage these risks. The proposed elements of this REMS program would include both a patient medication guide and a healthcare provider (HCP) communication plan. The goals of the proposed belatacept REMS would be to minimize the risk of PTLD and serious infections by educating HCPs and patients on the risk of their occurrence and ways to mitigate the impact of these adverse events should they occur. In addition, a thorough pharmacovigilance plan has been proposed that includes routine and enhanced safety monitoring, as well as four postmarketing research studies aimed at further characterizing these risks. ${ }^{41}$

In May 2010, the FDA delayed approval of this medication and asked the manufacturer to provide 36-months of follow-up data from the Phase III clinical studies to further evaluate the long-term effects of belatacept. The FDA also asked for information to support the manufacturer's proposed REMS. It is safe to say that when and if belatacept is approved by the FDA then it will require a REMS program.

Belatacept's role as a rescue therapy has been described in patient's suffering from mammalian target of rapamycin associated adverse effects, CNI-associated posttransplant thrombotic microangiography, and hemolytic uremic syndrome. ${ }^{42,43}$ Successful transition of a CNI-based immunosuppressive regimen to a belatacept-based regimen has previously been described. ${ }^{26}$ If approved by the FDA, belatacept's most immediate role might be that of a rescue therapy when traditional immunosuppressive regimens prove intolerable. It is important to note that a switch in immunosuppressive therapy from a CNI to belatacept does carry an increased risk of ACR as described in the analysis. ${ }^{26}$

The majority of trials summarized in this review combine belatacept with basiliximab induction therapy as well as mycophenolate mofetil and steroids for long-term maintenance immunosuppression. ${ }^{19,22,24,26}$ Ferguson et al performed an analysis that coupled belatacept with rabbit-antithymocyte globulin induction and a steroid withdrawal protocol. As previously discussed, the use of rabbit-antithymocyte globulin is associated with an increase in both malignancy 
and PTLD. ${ }^{25,38-40}$ The analysis only included RTRs who were known to be EBV seropositive pre-transplant. At the time of this review, no cases of PTLD have been described in either the $\mathrm{B}+\mathrm{SRL}$ or $\mathrm{B}+\mathrm{MMF}$ groups in this study. The two belatacept groups have also demonstrated similar rates of infection when compared with the standard TAC+MMF group. ${ }^{25}$ Use of rabbit-antithymocyte globulin as an induction therapy is a reasonable option for patients planned for long-term belatacept therapy if they are EBV seropositive prior to transplantation.

A clear disadvantage to CNI-based immunosuppressive regimens is the obligation of TDM. Constant intra- and interpatient pharmacokinetic variability insist that clinicians and patients remain diligent about appropriately drawing levels, avoiding food and drug interactions that potentially inhibit or induce drug metabolism, and constantly document changes in dosing throughout the life of the allograft. Barriers to TDM in both the outpatient and inpatient realms have been thoroughly described. ${ }^{44-47}$ These barriers are potentially avoided with the use of belatacept in that the pharmacokinetic profile demonstrates linear, zero-order elimination regardless of age, gender, or organ function. ${ }^{20}$ Pharmacodynamic monitoring of belatacept's saturation of the CD86 site on APCs has been described as a potentially meaningful assessment of effectiveness. ${ }^{18}$ However, no clinical trials of belatacept have implemented TDM as means of immunosuppressive management in patient and is therefore not recommended.

An obvious disadvantage of belatacept is the requirement of a local infusion-center, a hired home infusion service, or an infusion suite within a transplant center's clinic for administration. Without these essential resources, the use of belatacept is irrelevant. Patients and centers that have access to meet the appropriate infusion requirements have an opportunity to overcome issues of medication adherence. The requirement of monthly infusions at a local center could potentially lead to improved adherence to an immunosuppressive medication because a missed appointment is immediately recognized by clinicians. ${ }^{19}$ However, ensured adherence to oral medications that compliment belatacept-based immunosuppression cannot be guaranteed. Estimates of nonadherence in the transplant population range from $5 \%$ to $55 \%$ of all patients, and the impact of requiring one medication to be given as an infusion is arguable. ${ }^{48-52}$

The financial impact belatacept will have on the renal transplant patient, healthcare system, and both private and public insurance is difficult to discern. Both the preparation and administration require resources and facilities that provide the appropriate sterile environments that comply with current standards. Furthermore, the infusions should only be administered by staff that are both qualified and certified to do so. The cost of belatacept itself is undetermined at the time of this review. However, the incremental dosing of belatacept, one infusion every 4 weeks, may ease any financial burden on the patient and associated healthcare systems. An assessment of belatacept's pharmacokinetic profile after subcutaneous administration is currently being executed. Unfortunately, there are no available data from this analysis at the time of this review. If subcutaneous administration of belatacept is found to have a comparable pharmacokinetic profile with the IV administration it would introduce a potential bypass to many of belatacept's logistical disadvantages. For example, local-infusion centers, home infusion services, or need of an infusion suite would no longer be necessary. Self-administration of a subcutaneous injection would presumably soften the economic impact of belatacept and improve patients' quality of life.

Currently, based on the manufacturer's recommendation, the FDA is reviewing the LI dosing regimen of belatacept as an immunosuppressive regimen in kidney transplant recipients. The potential introduction of a novel biologic agent that offers a new mechanism of inhibiting cellular response is an exciting development in a field that has exhausted the current options. Although improvements in renal function have been well documented and are promising, the increased risk of ACR and malignancy associated with belatacept are certainly troubling. Unfortunately, the availability of longterm efficacy and safety outcomes is limited. The FDA has appropriately postponed a decision on belatacept's introduction to the market until such data does become available. If approved, caution in patients who are at an increased risk of malignancy, especially PTLD, is paramount. Also, despite improvements in allograft function compared with standard regimens, clinicians will be accepting an increased risk in the incidence and severity of ACR.

\section{Disclosure}

The authors do not have any disclosures in regards to the content of this manuscript.

\section{References}

1. Halloran PF. Immunosuppressive drugs for kidney transplantation. N Engl J Med. 2004;351:2715-2729. 
2. Allison JP. CD28-B7 interactions in T-cell activation. Curr Opin Immunol. 1994;6:414-419.

3. Anderson DE, Sharpe AH, Hafler DA. The B7-CD28/CTLA-4 costimulatory pathways in autoimmune disease of the central nervous system. Curr Opin Immunol. 1999;11:677-683.

4. Kremer JM, Westhovens R, Leon M, et al. Treatment of rheumatoid arthritis by selective inhibition of T-cell activation with fusion protein CTLA4Ig. N Engl J Med. 2003;349:1907-1915.

5. Genovese MC, Becker JC, Schiff M, et al. Abatacept for rheumatoid arthritis refractory to tumor necrosis factor alpha inhibition. $N$ Engl JMed. 2005;353:1114-1123.

6. Kremer JM, Dougados M, Emery P, et al. Treatment of rheumatoid arthritis with the selective costimulation modulator abatacept: twelve-month results of a Phase IIB, double-blind, randomized, placebo-controlled trial. Arthritis Rheum. 2005;52:2263-2271.

7. Kremer JM, Genant HK, Moreland LW, et al. Effects of abatacept in patients with methotrexate-resistant active rheumatoid arthritis: a randomized trial. Ann Intern Med. 2006;144:865-876.

8. Ruperto N, Lovell DJ, Quartier P, et al. Abatacept in children with juvenile idiopathic arthritis: a randomised, double-blind, placebo-controlled withdrawal trial. Lancet. 2008;372:383-391.

9. Larsen CP, Pearson TC, Adams AB, et al. Rational development of LEA29Y (belatacept), a high-affinity variant of CTLA4-Ig with potent immunosuppressive properties. Am J Transplant. 2005;5:443-453.

10. Turka LA, Linsley PS, Lin H, et al. T-cell activation by the CD28 ligand B7 is required for cardiac allograft rejection in vivo. Proc Natl Acad Sci U S A. 1992;89:11102-11105.

11. Lenschow DJ, Zeng Y, Thistlethwaite JR, et al. Long-term survival of xenogeneic pancreatic islet grafts induced by CTLA4lg. Science. 1992;257:789-792.

12. Wang D, Matsumoto R, You Y, et al. CD3/CD28 costimulation-induced NF-kappaB activation is mediated by recruitment of protein kinase C-theta, Bcl10, and IkappaB kinase beta to the immunological synapse through CARMA1. Mol Cell Biol. 2004;24:164-171.

13. McAdam AJ, Schweitzer AN, Sharpe AH. The role of B7 co-stimulation in activation and differentiation of CD4+ and CD8+ T cells. Immunol Rev. 1998;165:231-247.

14. Alegre ML, Frauwirth KA, Thompson CB. T-cell regulation by CD28 and CTLA-4. Nat Rev Immunol. 2001;1:220-228.

15. Schwartz RH. A cell culture model for T lymphocyte clonal anergy. Science. 1990;248:1349-1356.

16. Greene JL, Leytze GM, Emswiler J, et al. Covalent dimerization of CD28/CTLA-4 and oligomerization of CD80/CD86 regulate T cell costimulatory interactions. J Biol Chem. 1996;271:26762-26771.

17. Linsley PS, Greene JL, Brady W, Bajorath J, Ledbetter JA, Peach R. Human B7-1 (CD80) and B7-2 (CD86) bind with similar avidities but distinct kinetics to CD28 and CTLA-4 receptors. Immunity. 1994;1:793-801.

18. Latek R, Fleener C, Lamian V, et al. Assessment of belatacept-mediated costimulation blockade through evaluation of CD80/86-receptor saturation. Transplantation. 2009;87:926-933.

19. Vincenti F, Larsen C, Durrbach A, et al. Costimulation blockade with belatacept in renal transplantation. $N$ Engl J Med. 2005;353: $770-781$.

20. Zhou Z, Shen J, Kaul S, Pfister M, Roy A. Belatacept population pharmacokinetics in renal transplant patients [abstract]. In: American Transplant Congress 2010; San Diego, CA; 2010;1505.

21. Vincenti F, Blancho G, Durrbach A, et al. Five-year safety and efficacy of belatacept in renal transplantation. J Am Soc Nephrol. 2010;21(9): $1587-1596$.

22. Vincenti F, Charpentier B, Vanrenterghem Y, et al. A Phase III study of belatacept-based immunosuppression regimens versus cyclosporine in renal transplant recipients (BENEFIT study). Am J Transplant. 2010;10:535-546.

23. Metzger RA, Delmonico FL, Feng S, Port FK, Wynn JJ, Merion RM. Expanded criteria donors for kidney transplantation. Am J Transplant. 2003;3 Suppl 4:114-125.
24. Durrbach A, Pestana JM, Pearson T, et al. A Phase III study of belatacept versus cyclosporine in kidney transplants from extended criteria donors (BENEFIT-EXT study). Am J Transplant. 2010;10:547-557.

25. Ferguson R, Grinyo J, Vincenti F, et al. Immunosuppression with belatacept-based, corticosteroid-avoiding regimens in de novo kidney transplant recipients. Am J Transplant. 2011;11:66-76.

26. Rostaing L, Nainan G, del C Rial M, et al. Switch from a CNI- to a belatacept-based immunosuppressive regimen in kidney transplant recipients is safe and results in better renal function: 12 month results from a Phase II study [abstract]. In: American Transplant Congress 2010; San Diego, CA; 2010; 166.

27. Phan TG, O'Neill BP, Kurtin PJ. Posttransplant primary CNS lymphoma. Neuro Oncol. 2000;2:229-238.

28. Snanoudj R, Durrbach A, Leblond V, et al. Primary brain lymphomas after kidney transplantation: presentation and outcome. Transplantation. 2003;76:930-937.

29. Castellano-Sanchez AA, Li S, Qian J, Lagoo A, Weir E, Brat DJ. Primary central nervous system posttransplant lymphoproliferative disorders. Am J Clin Pathol. 2004;121:246-253.

30. Ferguson R. Acute rejection episodes - best predictor of long-term primary cadaveric renal transplant survival. Clin Transplant. 1994;8: 328-331.

31. Tesi RJ, Elkhammas EA, Henry ML, Davies EA, Salazar A, Ferguson RM. Acute rejection episodes: best predictor of long-term primary cadaveric renal transplant survival. Transplant Proc. 1993;25: 901-902.

32. Flechner SM, Modlin CS, Serrano DP, et al. Determinants of chronic renal allograft rejection in cyclosporine-treated recipients. Transplantation. 1996;62:1235-1241.

33. Pirsch JD, Ploeg RJ, Gange S, et al. Determinants of graft survival after renal transplantation. Transplantation. 1996;61:1581-1586.

34. Meier-Kriesche HU, Schold JD, Srinivas TR, Kaplan B. Lack of improvement in renal allograft survival despite a marked decrease in acute rejection rates over the most recent era. Am J Transplant. 2004;4: 378-383.

35. Gill JS, Tonelli M, Mix CH, Pereira BJ. The change in allograft function among long-term kidney transplant recipients. J Am Soc Nephrol. 2003; 14:1636-1642.

36. Go AS, Chertow GM, Fan D, McCulloch CE, Hsu CY. Chronic kidney disease and the risks of death, cardiovascular events, and hospitalization. $N$ Engl J Med. 2004;351:1296-1305.

37. Anavekar NS, McMurray JJ, Velazquez EJ, et al. Relation between renal dysfunction and cardiovascular outcomes after myocardial infarction. N Engl J Med. 2004;351:1285-1295.

38. Cockfield SM, Preiksaitis JK, Jewell LD, Parfrey NA. Post-transplant lymphoproliferative disorder in renal allograft recipients. Clinical experience and risk factor analysis in a single center. Transplantation. 1993;56:88-96.

39. Swinnen LJ, Costanzo-Nordin MR, Fisher SG, et al. Increased incidence of lymphoproliferative disorder after immunosuppression with the monoclonal antibody OKT3 in cardiac-transplant recipients. N Engl J Med. 1990;323:1723-1728.

40. Bustami RT, Ojo AO, Wolfe RA, et al. Immunosuppression and the risk of post-transplant malignancy among cadaveric first kidney transplant recipients. Am J Transplant. 2004;4:87-93.

41. Belatacept (BMS-224818). FDA's Cardiovascular and Renal Drugs Advisory Committee. Briefing Document for March 2010 Meeting. 2010. Available from: http://www.fda.gov/downloads/AdvisoryCom mittees/ CommitteesMeetingMaterials/Drugs/CardiovascularandRenalDrugsAd visoryCommittee/UCM201859.pdf. Accessed November 15, 2010.

42. Midtvedt K, Bitter J, Dørje C, Stenstrøm J, Bjørneklett R, Holdaas H. Belatacept as Rescue Treatment for Recurrence of Haemolytic-Uremic Syndrome after Renal Transplantation [abstract]. In: American Transplant Congress 2009; Boston, MA; 2009; 766.

43. Ashman N, Chapagain A, Dobbie H, Raftery MJ, Sheaff MT, Yaqoob MM. Belatacept as maintenance immunosuppression for postrenal transplant de novo drug-induced thrombotic microangiopathy. Am J Transplant. 2009;9:424-427. 
44. Masuda S, Inui K. An up-date review on individualized dosage adjustment of calcineurin inhibitors in organ transplant patients. Pharmacol Ther. 2006;112:184-198.

45. Kuypers DR. Influence of interactions between immunosuppressive drugs on therapeutic drug monitoring. Ann Transplant. 2008; 13:11-18.

46. Budde K, Glander P. Pharmacokinetic principles of immunosuppressive drugs. Ann Transplant. 2008;13:5-10.

47. Holt DW. Therapeutic drug monitoring of immunosuppressive drugs in kidney transplantation. Curr Opin Nephrol Hypertens. 2002;11: 657-663.

48. Bunzel B, Laederach-Hofmann K. Solid organ transplantation: are there predictors for posttransplant noncompliance? A literature overview. Transplantation. 2000;70:711-716.
49. De Geest S, Borgermans L, Gemoets H, et al. Incidence, determinants, and consequences of subclinical noncompliance with immunosuppressive therapy in renal transplant recipients. Transplantation. 1995;59: 340-347.

50. Vasquez EM, Tanzi M, Benedetti E, Pollak R. Medication noncompliance after kidney transplantation. Am J Health Syst Pharm. 2003;60: 266-269.

51. Chisholm MA, Mulloy LL, DiPiro JT. Comparing renal transplant patients' adherence to free cyclosporine and free tacrolimus immunosuppressant therapy. Clin Transplant. 2005;19:77-82.

52. Kiley DJ, Lam CS, Pollak R. A study of treatment compliance following kidney transplantation. Transplantation. 1993;55:51-56.

\section{Publish your work in this journal}

Transplant Research and Risk Management is an international, peerreviewed open access journal focusing on all aspects of transplantation and risk management to achieve optimal outcomes in the recipient improving survival and quality of life. The journal welcomes submitted papers covering original research, basic science, clinical studies, reviews \& evaluations, guidelines, expert opinion and commentary, case reports and extended reports. The manuscript management system is completely online and includes a very quick and fair peer-review system, which is all easy to use. Visit http://www.dovepress.com/ testimonials.php to read real quotes from published authors.

Submit your manuscript here: http://www.dovepress.com/transplant-research-and-risk-management-journal 